\title{
Little
}

\author{
Irene Heim \\ Massachusetts Institute of Technology
}

\section{An Ambiguity}

Seuren (1979) and Rullmann (1995) observed an ambiguity in less-comparatives which contain possibility operators.

(1) Lucinda is driving less fast than is allowed on this highway.

One reading of Rullmann's example (1) says that Lucinda is not driving as fast as she is legally entitled to. E.g., if the posted speed limit is $65 \mathrm{mph}$, this reading claims that her speed is below $65 \mathrm{mph}$. There is also another reading, which says that Lucinda's speed is impermissibly low. E.g., if the highway has a posted minimum speed of $40 \mathrm{mph}$, this amounts to claiming that her speed is below $40 \mathrm{mph}$. As Rullmann notes, according to the second reading, Lucinda is breaking the law, while the first reading implies no such thing.

There also is ambiguity in certain examples involving modal operators and the word little.

a. We can grow very little.

b. I didn't realize how little I can pay.

c. It's a shame that they let the students write so little!

To bring out one reading af (2a), continue it with ... or we can grow a lot - it's entirely up to us. Here (2a) means that growing very little is a possibility. For the other reading, continue with ... before we run out of space. Now (2a) means that growing very little is, in effect, a necessity: in view of the space constraints, it is not possible for us to grow more than very little. - For (2b), a disambiguating continuation might be ... and still get a good-quality drill. Here I am saying that I thought I would have to pay more. A different disambiguating continuation for (2b) is I thought I still had lots of money left. Here the meaning is that I thought I would be able to pay more. - To appreciate the ambiguity in (2c), imagine that the students are eager to write long papers, but are prevented from doing so by the enforcement of a strict page limit. If you disapprove of this, you might express

Previous versions of this paper were presented in colloquia at UConn, Rutgers, Penn, UMass, Tübingen, and at the Amsterdam Colloquium. I thank the hosts and audiences of these events, as well as those of SALT 16 in Tokyo. I am especially grateful for oral and written feedback from Cécile Meier, Eric McCready, Roger Schwarzschild, Karina Wilkinson, and Yoad Winter. 
this by uttering (2c). What you are saying is that the students shouldn't be curtailed in their eagerness, they should be allowed to write more. But now imagine instead that the students dread writing and avoid it whenever they can. You believe it's important for them to learn it and there should be requirements that ensure extensive practice. Unfortunately, your opinion did not prevail in the currriculum committee and the policy adopted requires only a very small amount of writing. You utter (2c) then to register disappointment. What you are saying this time is that they should have been required to write more.

I propose that the ambiguities in (1) and (2) all have the same source, and that the key to understanding them is an analysis of the degree-word little and its scopal interaction with the modal operator. Less, I assume, is a suppletive form for the comparative of little, so the analysis of little is prior, and the SeurenRullmann ambiguity in comparatives is a special case.

\section{Little as Degree Negation}

What is little? In the use of it that interests us, ${ }^{1}$ it's a measure phrase on a par with much. It is gradable and combines with degree morphemes such as so, too, how, and it goes with mass nouns or gradable verbs.
a. little water
much water
how little water
how much water
too little water
too much water
less water
more water
b. grow very little
grow very much
grow so little
grow so much
grow the least
grow the most

(Some examples, e.g., write so little, are ambiguous between a transitive verb followed by null-headed mass NP and an intransitive gradable verb with an adverb.) I suggest that little also occurs as a measure phrase for adjectives and adverbs, although the paradigm in English is defective here and only the suppletive comparative and superlative forms (less tall, least tall) are attested. ${ }^{2}$

I follow the common practice of treating gradable adjectives (and adverbs) as relations between entities (individuals or events) and degrees. I also assume

\footnotetext{
${ }^{1}$ The adjective meaning 'small' (as in little boy) will not be considered here.

${ }^{2}$ The only exception are adjectival passive participles (little known), as pointed out to me by A. Prince. This limitation is not seen e.g. in German. I will view it as an idiosyncrasy of morphology and pursue a semantic analysis that allows the full paradigm with adjectives as well as with mass nouns and gradable verbs.
} 
that mass nouns denote relations between entities and degrees (amounts), and I posit degree arguments for suitable verbs. ${ }^{3}$
a. $\llbracket$ fast $\rrbracket=\lambda \mathrm{d} . \lambda \mathrm{x} . \operatorname{Speed}(\mathrm{x}) \geq \mathrm{d}$
b. $\llbracket$ water $\rrbracket=\lambda \mathrm{d} . \lambda \mathrm{x} . \mathrm{x}$ is water and $\operatorname{Amount}(\mathrm{x}) \geq \mathrm{d}$
c. $\llbracket$ grow $\rrbracket=\lambda \mathrm{d}$. $\lambda \mathrm{x}$. Growth $(\mathrm{x}) \geq \mathrm{d}$

The degree-argument slots of all these predicates may be filled or bound by various types of degree phrases (DegPs), such as measure phrases (five feet), degree particles or the complex phrases these head (too, so, -er + thancomplement, -est), an zero positive morpheme POS, or a visible or invisible whelement (how,wh). With at most the exception of some of the simplest measure phrases, these DegPs do not refer to degrees. Rather, they should be viewed as generalized quantifiers over degrees of one sort or another. For example, a credible meaning for the DegP -er than $25 \mathrm{mph}$ is the function of type $<\mathrm{dt}, \mathrm{t}>$ in (5). (I will say more about the precise semantic analysis of -er; this is just to illustrate the framework.) Such DegPs will then QR to remedy a type-mismatch.

$$
\llbracket \text { er than } 25 \mathrm{mph} \rrbracket=\lambda \mathrm{P}_{<\mathrm{d}, \mathrm{t}>\cdot \max (\mathrm{P})>25 \mathrm{mph}}
$$

As noted in some of the earliest syntax literature on degree constructions, DegPs not only can be complex, but complex enough to allow recursion. This occurs, for example, in differential comparatives, where the comparative morpheme itself introduces a new degree argument for a difference, and this in turn can be a complex DegP.

I am as much taller than you are as she is.

Here the degree argument of the adjective tall is saturated by the DegP er than you are (tall), which in turn selects for its own degree argument, which is provided by the DegP as as she is (taller than you are tall). We have nested DegPs underlyingly and a kind of inverse linking configuration at LF.
a. I am [AP [DegP [DegP as as she is ...] er than you are ...] tall]
b. LF: [as as she is ... $]_{1}\left[\mathrm{t}_{1} \text { er than you are ... }\right]_{2} \mathrm{I}$ am $\left[\mathrm{t}_{2}\right.$ tall $]$

With these preliminaries in place, I present my analysis of little. I propose that little, being gradable, takes a degree argument. Together with it, it forms what I call the little-phrase. This is a generalized quantifier over degrees, and it serves as the degree argument of the predicate that little combines with. To take a simple case, a sentence like This weighs little gets the following analysis.

\footnotetext{
${ }^{3}$ This is just a convenient way to abstract away from more complex internal structure.
} 

a. this weighs [DegP $[\mathrm{DegP} P O S]$ little]
b. LF: $\operatorname{POS}_{1}\left[\mathrm{t}_{1} \text { little }\right]_{2}$ this weighs $\mathrm{t}_{2}$

On the semantic side, I treat little as a kind of negation. The intuition behind the entry in (9) is that 'd little' means 'not to degree d'.

$$
\llbracket l i t t l e \rrbracket=\lambda \mathrm{d} . \lambda \mathrm{P}_{<\mathrm{d}, \mathrm{t}>} . \mathrm{P}(\mathrm{d})=0
$$

To complete the analysis of the example, I adopt von Stechow's (2005) analysis of the Positive morpheme.

$$
\llbracket P O S \rrbracket^{\mathrm{c}}=\lambda \mathrm{P}_{<\mathrm{d}, \mathrm{t}>} . \mathrm{L}_{\mathrm{c}} \subseteq \mathrm{P}
$$

$\mathrm{L}_{\mathrm{c}}$ is a contextually given "delineation interval", corresponding to the "neutral" zone on the relevant scale - here to the region on the weight scale where things count as neither light nor heavy. We thus compute the truth-conditions (11) for the LF (8b). By two lambda-conversions, we derive that the weight of this is below the (bottom edge of the) delineation interval, hence this counts as light.

$$
\begin{aligned}
& \left.\left[\lambda \mathrm{P}_{<\mathrm{d}, \mathrm{t}>} . \mathrm{L}_{\mathrm{c}} \subseteq \mathrm{P}\right]\left(\lambda \mathrm{d} .\left[\lambda \mathrm{Q}_{<\mathrm{d}, \mathrm{t}>} . \mathrm{Q}(\mathrm{d})=0\right](\lambda \mathrm{d} \text {. Weight(this }) \geq \mathrm{d}\right)\right) \\
& =\quad \text { Weight(this })<\mathrm{L}_{\mathrm{c}}
\end{aligned}
$$

In the next section, I will analyze the ambiguities introduced in section 1. The key will be the ability of the little-phrase to take different scopes relative to the modal operator. I will also have to make some assumptions about the comparative, so, and how constructions that combine with little in the examples.

\section{The Ambiguity as a Scope Ambiguity}

Let us take a closer look at (2a), We can grow very little. The DegP very little starts out as the degree-argument of grow, but at LF is displaced to an interpretable position. There are two options, below or above can. ${ }^{4}$

a. can very ${ }_{1}\left[\mathrm{t}_{1} \text { little }\right]_{2}\left[\right.$ we grow $\left.\mathrm{t}_{2}\right]$

b. very $_{1}\left[\mathrm{t}_{1} \text { little }\right]_{2}$ can $\left[\right.$ we grow $\left.\mathrm{t}_{2}\right]$

Let us work out the denotations for these two structures. Again with von Stechow (2005), I assume that very is like POS, except referring to a larger delineation interval $\mathrm{L}_{\mathrm{very}, \mathrm{c}}$ that properly includes $\mathrm{L}_{\mathrm{c}}$. In this case, this is the region on the

\footnotetext{
${ }^{4}$ Very also QRs, but its scope relative to can makes no truth-conditional difference (Heim 2001).
} 
growth scale within which growth counts as neither very small nor very large. Let's also assume we refers to a company, and growth is measured in terms of number of added employees. So the measure function $\mathrm{Growth}_{\mathrm{w}}$ maps companies $\mathrm{x}$ to the number of employees that $\mathrm{x}$ adds in world $\mathrm{w}$. The shared elementary clause we grow $t_{2}$ then has the interpretation in (13a). In (12a), this combines first with the little-phrase, which introduces negation, and subsequently with the modal, which contributes existential quantification over possible worlds, as shown in (13b). (I use Acc for whatever the relevant accessibility relation may be.) For (12b), these operations apply in the opposite order, as in (13c).

a. 【we grow $t_{2} \rrbracket^{\mathrm{w}, \mathrm{g}}=\operatorname{Growth}_{\mathrm{w}}(\mathrm{we}) \geq \mathrm{g}(2)$

b. $\llbracket$ very $_{1} \mathrm{t}_{1}$ little $_{2}$ we grow $\mathrm{t}_{2} \rrbracket^{\mathrm{w}}=\mathrm{Growth}_{\mathrm{w}}(\mathrm{we})<\mathrm{L}_{\mathrm{very}, \mathrm{c}}$ $\llbracket$ can very $\mathrm{t}_{1}$ little $_{2}$ we grow $\mathrm{t}_{2} \rrbracket^{\mathrm{w}}=$

$\exists w^{\prime} \in \operatorname{Acc}(w): \operatorname{Growth}_{\mathrm{w}^{\prime}}($ we $)<\mathrm{L}_{\mathrm{very}, \mathrm{c}}$

c. 【can we grow $\mathrm{t}_{2} \rrbracket^{\mathrm{w}, \mathrm{g}}=\exists \mathrm{w}^{\prime} \in \operatorname{Acc}(\mathrm{w}):$ Growth $_{\mathrm{w}}(\mathrm{we}) \geq \mathrm{g}(2)$

【very $\mathrm{t}_{1}$ little $_{2}$ can we grow $\mathrm{t}_{2} \rrbracket^{\mathrm{w}}=$

$\neg \exists \mathrm{w}^{\prime} \in \operatorname{Acc}(\mathrm{w}): \operatorname{Growth}_{\mathrm{w}^{\prime}}(\mathrm{we}) \geq \mathrm{L}_{\mathrm{very}, \mathrm{c}}=$

$\forall \mathrm{w}^{\prime} \in \operatorname{Acc}(\mathrm{w}): \operatorname{Growth}_{\mathrm{w}^{\prime}}(\mathrm{we})<\mathrm{L}_{\mathrm{very}, \mathrm{c}}$

So (12a) means that in some accessible worlds, our growth remains below the treshold value, i.e., is very small. This does not preclude that in other accessible worlds it is higher. This is the reading brought out by our first continuation, but we can also grow a lot. (12b), on the other hand, means that in every accessible world our growth falls in the "very small" range. This is the reading brought out by ... before we run out of space (which suggests an accessibility relation under which the accessible worlds are those where we continue to fit into our space).

Before we proceed to more complex examples, I will draw up a handy diagram. On the horizontal axis is a range of possible worlds, which differ as to how much we grow in them. I indicate by underlining which of these are accessible (from the actual world). The vertical axis corresponds to the scale of amounts of growth, and I have plotted the number of employees by which our company grows in each world.

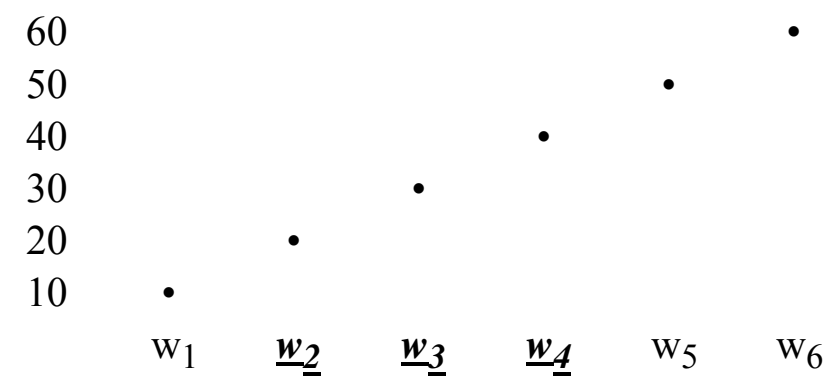

As you see, we grow by $10 \mathrm{n}$ employees in each world $\mathrm{w}_{\mathrm{n}}$, and the accessible worlds are $\mathrm{w}_{2}$ through $\mathrm{w}_{4}$. This represents a state of affairs where we can grow 
by 20,30 , or 40 people, but it is not possible for us to grow by more than 40 , nor to grow by less than 20. The truth-conditions computed in (13) then are sensitive to the location of $\mathrm{L}_{\mathrm{very}, \mathrm{c}}$. The reading in (13b) will be true in this scenario if its bottom edge is higher than 20, i.e., if at least the smallest of our possible growth rates counts as very small. The reading in (13c) will be true if it's higher than 40, i.e., if even our highest possible growth rate still counts as very small.

Let us next look at the embedded clause in example (2b), I didn't realize how little I can pay. We have a pre-wh-movement structure for the how-clause as in (15).

can [I pay [how little]]

At LF, both DegPs are displaced for interpretability. How has to be at the edge of the $\mathrm{CP}$, but the little-phrase again has two options:

\section{a. how 1 can $\left[\mathrm{t}_{1} \text { little }\right]_{2}$ I pay $\mathrm{t}_{2}$}

b. how ${ }_{1}\left[\mathrm{t}_{1} \text { little }\right]_{2}$ can I pay $\mathrm{t}_{2}$

Working out the denotations for these two structures, we treat how as vacuous, so both will denote sets of degrees (monetary values). Payment ${ }_{\mathrm{w}}$ is the function that maps $\mathrm{x}$ to the amount $\mathrm{x}$ pays in $\mathrm{w}$. The computations are as in the last example.
a. $\quad \llbracket I$ pay $t_{2} \rrbracket^{\mathrm{W}, \mathrm{g}}=$ Payment $_{\mathrm{W}}(\mathrm{I}) \geq \mathrm{g}(2)$
b. $\left.\llbracket(16 \mathrm{a}) \rrbracket^{\mathrm{w}}=\left\{\mathrm{d}: \exists \mathrm{w}^{\prime} \in \operatorname{Acc}(\mathrm{w}): \operatorname{Payment}_{\mathrm{w}},(\mathrm{I})<\mathrm{d}\right]\right\}$
c. $\llbracket(16 b) \rrbracket^{\mathrm{w}}=\left\{\mathrm{d}: \forall \mathrm{w}^{\prime} \in \operatorname{Acc}(\mathrm{w}):\right.$ Payment $\left._{\mathrm{w}},(\mathrm{I})<\mathrm{d}\right\}$

To appreciate this result, let's use our diagram (14), reinterpreted for the case at hand. Let the vertical axis now correspond to a scale of monetary values, $\$ 10$, $\$ 20$, and so on. The accessible worlds still are $\mathrm{w}_{2}$ through $\mathrm{w}_{4}$, so we are looking at a state of affairs where I can pay $\$ 20, \$ 30$, or $\$ 40$, but not more than $\$ 40$ or less than $\$ 20 .^{5}$ The sets computed in $(17 \mathrm{~b}, \mathrm{c})$ correspond to certain intervals in this model: (17b) contains all the values below which I pay in at least one accessible world; so this is the open interval $(\$ 20, \infty)$, bounded from below by my required minimum payment. In $(17 \mathrm{c})$, we get only the values below which I pay in every accessible world, thus the interval $(\$ 40, \infty)$, whose lower bound is my possible maximum payment.

To see if this captures the two readings we identified intuitively for the complete sentence (2b), we must say something about the embedding construction

${ }^{5} \mathrm{I}$ am leaving open here what sort of accessibility relation this is. For obvious pragmatic reasons, positing a non-null lower limit on how much I can pay fits better with a deontic or teleological reading, whereas an upper limit is more natural with an ability reading. See Rullmann (1995) for discussion of how the pragmatic plausibility of the existence of minima or maxima governs the availability of each reading. 
I didn't realize. This should ideally derive in a principled fashion from the semantics of questions or exclamatives and the verbs that embed them, but I will make do here with an ad hoc semantics. Let's say that when I-didn't-realize combines with a property of degrees $P$, the meaning is that I thought there were fewer degrees with property $P$ than there actually are. I.e., the actual extension of $P$ is a proper superset of the expected extension. A bit more formally:

$$
\llbracket I \text {-didn't-realize } \rrbracket=\lambda \mathrm{P}_{<\mathrm{s}, \mathrm{dt}>} . \forall \mathrm{w} \in \operatorname{Exp}: \mathrm{P}(\mathrm{w}) \subset \mathrm{P}(@) \text {, }
$$
where Exp is the set of worlds conforming to my (prior) expectation

For reading (17b), the actual extension of the how-clause we computed was $(\$ 20, \infty)$. So if the expected extension was smaller than this, it was perhaps $(\$ 30, \infty)$ or $(\$ 40, \infty)$. Such an expectation would have been correct if my required minimum payment had been higher than it was in fact. The sentence on this reading implies that I expected I would be required to pay more. - For reading $(17 \mathrm{c})$, on the other hand, the actual extension of the how-clause that we computed was $(\$ 40, \infty)$. If the expected extension again was smaller than this, it was perhaps $(\$ 50, \infty)$ or $(\$ 60, \infty)$. This expectation would have been borne out in a world in which my maximal possible payment would have been higher. So on this reading, I thought I would be able to pay more.

The analysis of the ambiguity in (2c) will be similar. An ad hoc semantics for It's a shame that ... so ... would compose this phrase with a property of degrees, with the meaning being that in the kinds of worlds I would have approved of, that property would have had a smaller extension. We can recycle our same old diagram to make the y-axis stand for numbers of pages (a measure of amounts of writing). With the accessible worlds still $\mathrm{w}_{2}$ through $\mathrm{w}_{4}$, this depicts a situation where the students are forced to write at least 20 pages and are not allowed to write more than 40 . Scoping little below let, we express a property of degrees whose actual extension is $(20 \mathrm{pp}, \infty)$. If I'd prefer a smaller extension, I'd prefer a situation where the required minimal amount of writing is more than 20 pages. This is the reading where I am appalled at the fact that the students can get away with so little writing practice. - But if little outscopes let, we express a property of degrees whose actual extension is $(40 \mathrm{pp}, \infty)$. If again I'd prefer a smaller extension, then I'd prefer a situation where the page limit (the allowable maximal amount of writing) is higher than 40 pages. This is the reading where I am appalled at the fact that the students' prolixity is being constrained.

A fuller analysis of the how and so constructions in these examples probably raises non-trivial and interesting issues, but I won't pursue these in this paper. Instead I will now turn to the less-comparatives discussed by Rullmann. In his example (1) about Lucinda on the highway, we have at least this much structure on the matrix clause level: 
Recall that I take less to spell out little+er. I also follow the line of grouping er and the superficially extraposed than-clause into a unit (henceforth the er-phrase). (19) is not yet the complete structure for the sentence, because we haven't yet parsed the than-clause. On a first pass of syntactic analysis, this is a wh-clause with a subject gap, presumably the same as the overt version than what is allowed. As with Comparative Deletion constructions in general, however, additional structure must be posited, at least on the LF-level, to obtain an interpretable configuration, with a variable of the semantic type of degrees. How this works and is supported by general processes of ellipsis or other structurebuilding is a complicated topic in the syntax of comparatives. Here I simply assume that allowed has a covert complement which is a copy of material that is overt in the matrix. Specifically, I posit a clause below allowed that is just like the matrix clause, except with a wh (empty operator) in the place of the er-phrase.

\section{Lu drive [[er than allowed Lu drive wh little fast] little] fast}

From this structure, with all DegPs in situ, interpretable LFs are derived by QRing the DegPs to the edges of suitable clausal domains. In the matrix clause, we have no other relevant scopal items, so the only option is as in (21).

$[\text {-er than ... }]_{1}\left[\mathrm{t}_{1} \text { little }\right]_{2}$ Lu drive $\mathrm{t}_{2}$ fast

In the than-clause, the wh has to move to the top, but for the little-phrase, I again postulate two possible scopes, below and above allowed.

a. $\mathrm{wh}_{3}$ allowed $\left[\mathrm{t}_{3} \text { little }\right]_{4}$ Lu drive $\mathrm{t}_{4}$ fast

b. $\mathrm{wh}_{3}\left[\mathrm{t}_{3} \text { little }\right]_{4}$ allowed Lu drive $\mathrm{t}_{4}$ fast

For the semantic computation, we have everything but a meaning for er in place. Er is taking two arguments, both properties of degrees. One of these properties is expressed in the main clause, by the degree-abstract resulting from the movement of the er-phrase, as seen in (21). This is essentially the negation of the degree-predicate $\lambda_{2}$. Lu drive $t_{2}$ fast. The latter denotes the interval ( 0 , Speed $\left._{@}(\mathrm{Lu})\right]$ (where @ is the actual world and $\operatorname{Speed}_{\mathrm{w}}(\mathrm{x})$ is x's driving speed in w). Negating with little yields the complementary interval $\left(\operatorname{Speed}_{\varrho}(\mathrm{Lu}), \infty\right)$. Working out the denotations of $(22 \mathrm{a}, \mathrm{b})$ is parallel to our earlier computations, and we can once again use the diagram in (14), this time reading the numbers on the $\mathrm{y}$-axis as speeds such as $10 \mathrm{mph}, 20 \mathrm{mph}$. With the accessible worlds being $\mathrm{w}_{2}$ through $\mathrm{w}_{4}$, the prescribed minimum speed thus is $20 \mathrm{mph}$ and the speed limit is $40 \mathrm{mph}$. The sets of degrees denoted by $(22 \mathrm{a}, \mathrm{b})$ then are the intervals $(20 \mathrm{mph}, \infty)$ and $(40 \mathrm{mph}, \infty)$ respectively.

Now what sort of semantics do we need for er in order to capture the intended meanings for the complete sentence? For the scope order in (22a), we 
want the meaning to be that Lucinda's actual speed is below the posted minimum speed, i.e., below $20 \mathrm{mph}$. The reverse scopal order in (22b) should mean that her actual speed is below the posted maximum speed, i.e., below 40mph. Effectively, then, we are always comparing the bottom egdes of the two intervals that are the arguments of er, and in each case are claiming that the bottom edge of the mainclause interval is below the bottom edge of the than-clause interval. An entry which encodes this directly would be (23).

$$
\llbracket e r \rrbracket=\lambda \mathrm{P}_{<\mathrm{d}, \mathrm{t}>} . \lambda \mathrm{Q}_{<\mathrm{d}, \mathrm{t}>} \text {. lower-bound(Q) }<\text { lower-bound(P) }
$$

This entry, however, would not work for ordinary (more-) comparatives like John is faster than Mary (is fast). There we compare the upper edges of two intervals that are initial segments of the scale, so we need something more like (24).

$$
\llbracket e r \rrbracket=\lambda \mathrm{P} \cdot \lambda \mathrm{Q} \cdot \max (\mathrm{Q})>\max (\mathrm{P})
$$

Luckily, (23) and (24) can be collapsed into a single entry, and this is my official proposal.

$$
\llbracket e r \rrbracket=\lambda \mathrm{P}_{<\mathrm{d}, \mathrm{t}>} \cdot \lambda \mathrm{Q}_{<\mathrm{d}, \mathrm{t}>. .} \mathrm{P} \subset \mathrm{Q}
$$

When we compare two initial segments of a degree scale, the first will be a proper subset of the second just in case the right egde (maximum or upper bound) of the first is below the right edge of the second. But when we compare two final segments, then the first is a proper subset of the second iff its left edge (minimum or lower bound) is above the left edge of the second. So (25) works correctly for both more-comparatives and less-comparatives.

To sum up this section, I have shown how to conceive of the ambiguities presented at the beginning of this paper as ambiguities of scope. The relevant two scope-bearing items are the possibility operator and the item little, which I analyze as expressing negation. For the ambiguous examples with very little, how little and so little, I gave sketches of how the ambiguous scope of little is causing the perceived ambiguities in the sentence as a whole. For the ambiguous lesscomparative, I showed how less can be decomposed into little and a general meaning for er which is common to more-comparatives and less-comparatives. The proposal makes various predictions which I would like to explore in the remainder of the paper. At the same time, I want to compare it to the proposals of Rullmann, from whom I have borrowed the most essential features and insights. 


\section{Rullmann}

Rullmann (1995) develops two analyses for the ambiguity in less-comparatives, one of them employing decomposition of less, ${ }^{6}$ the other one not. For reasons of space, I won't discuss his non-decompositional analysis (though it is the one he favors). His decompositional analysis resembles mine in that it decomposes less, but also differs, in that it doesn't employ a strictly compositional semantics. Although less is broken down into er and little, and although the position of little at LF is what governs the ambiguity, the morpheme little is not given a meaning of its own. The smallest meaningful units consist of little plus another morpheme.

Here is how it works concretely. The surface string less fast is the result of spelling out three morphemes, er, little, and fast. In the syntactic derivation and at LF, however, either little+er forms a unit to the exclusion of fast, or else little+fast forms a unit to the exclusion of er. The two LFs of the Lucindasentence differ in this way.

a. [little+er than $w_{2}$ allowed Lu drive $t_{2}$ fast $]_{1}$ Lu drive $t_{1}$ fast

b. [er than $w_{2}$ allowed Lu drive $t_{2}$ little + fast $]_{1}$ Lu drive $t_{1}$ little + fast

As in my analysis, the reconstructed complement of allowed is a perfect match of the matrix clause minus the er-phrase. Here, therefore, it contains a copy of little if and only if little is grouped with the adjective. The semantics that goes with these LFs uses the following entries, which I will elucidate as we need them. ${ }^{7}$
a. $\llbracket e r \rrbracket=\lambda \mathrm{P}_{<\mathrm{d}, \mathrm{t}>} \cdot \lambda \mathrm{Q}_{<\mathrm{d}, \mathrm{t}>} \cdot \max (\mathrm{Q})>\max (\mathrm{P})$
b. $\llbracket$ little $+e r \rrbracket=\lambda \mathrm{P}_{<\mathrm{d}, \mathrm{t}\rangle} \cdot \lambda \mathrm{Q}_{<\mathrm{d}, \mathrm{t}>} \cdot \max (\mathrm{Q})<\max (\mathrm{P})$
c. $\llbracket f a s t \rrbracket^{\mathrm{w}}=\lambda \mathrm{d}$. $\lambda \mathrm{x}$. $\operatorname{Speed}_{\mathrm{w}}(\mathrm{x})=\mathrm{d}$
d. $\llbracket$ little fast $\rrbracket^{\mathrm{w}}=\lambda \mathrm{d} \cdot \lambda \mathrm{x} \cdot \operatorname{Speed}_{\mathrm{w}}(\mathrm{x})=-\mathrm{d}$

To see how Rullmann gets $(26 \mathrm{a}, \mathrm{b})$ to express the two readings of (1), let's first look at (26a). This LF features the (morphologically complex but semantically simple) operator in (27b), which compares the maxima of two sets of degrees, requiring the maximum of the main-clause set to be below the maximum of the than-clause set. What is in these sets? The main clause of (26a) is $\lambda_{1}$. $L u$ drive $t_{1}$ fast, which, given the adjective entry in $(27 \mathrm{c})$ denotes $\left\{\operatorname{Speed}_{\circledast}(\mathrm{Lu})\right\}$, the singleton of Lu's actual speed, whose maximum is $\operatorname{Speed}_{@}(\mathrm{Lu})$. In the thanclause, $\lambda_{2}$. allowed [Lu drive $t_{2}$ fast], the possibility operator gives us the union of the singletons of Lu's speeds in all the accessible worlds. In our model that's

\footnotetext{
${ }^{6}$ Rullmann credits this analysis to a suggestion by Barbara Partee.

${ }^{7}$ These are not literally Rullmann's entries. I take some liberties with the technical execution of his proposal.
} 
\{20mph, 30mph, 40mph , with a maximum of $40 \mathrm{mph}$. So $(26 \mathrm{a})$ is true iff Speed $_{@}(\mathrm{Lu})<40 \mathrm{mph}$, i.e., if Lu drives below the permitted maximum speed.

The analysis of the less-than-minimum reading is a bit more involved. The LF in (26b) does not contain the adjective fast at all as a meaningful unit, rather it contains little+fast. Rullmann thinks of this as the antonym of fast, which might also surface as slow (a point which I will return to). Following a common idea about the antonymy-relation, he therefore assumes that little+fast uses a measure function with a range isomorphic to the one used by fast, except with an inverse ordering. I have chosen here to implement this in a concrete fashion, by identifying the arguments of fast with positive numbers and the arguments of little+fast with negative numbers, each in their canonical order. So

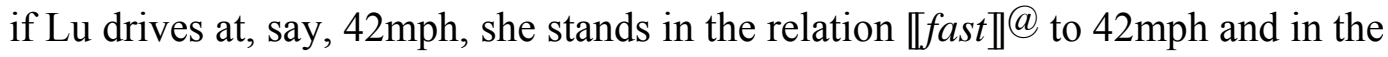
relation【little+fast》@ to $-42 \mathrm{mph}$. This said, we can compute the truthconditions for (26b). The main clause, $\lambda_{1}$. Lu drive $t_{1}$ little+fast, denotes the singleton $\left\{-\operatorname{Speed}_{@}(\mathrm{Lu})\right\}$. The than-clause, $\lambda_{2}$. allowed [Lu drive $t_{2}$ little+fast], denotes the union of the negative speeds in each accessible world, i.e., $\{-20 \mathrm{mph}$, $-30 \mathrm{mph},-40 \mathrm{mph}\}$ in our model. The comparison operator in (27b) is er, which requires the maximum of the main-clause set to exceed the maximum of the thanclause set. This means that $-\operatorname{Speed}_{@}(\mathrm{Lu})>-20 \mathrm{mph}$, or equivalently, $\operatorname{Speed}_{@}(\mathrm{Lu})<20 \mathrm{mph}$. I.e., Lu falls short of the lowest speed that's allowed.

A couple of comments are in order. First, Rullmann's analysis of adjectives (and other gradable predicates) differs from mine in that he relates each object to a unique point on the scale, not to a whole interval (initial segment of the scale). Note the appearance of ' $=$ ' in (27c) where I had ' $\geq$ ' in (4a). This difference is not actually relevant in the analysis of greater-than-maximum readings. ${ }^{8}$ It is crucial, however, for the interpretation of (27b). Once we map all the speeds to their negative images, we don't want intervals $\left[-\operatorname{Speed}_{\mathrm{w}}(\mathrm{Lu}), 0\right)$ instead of singletons $\left\{-\operatorname{Speed}_{\mathrm{w}}(\mathrm{Lu})\right\}$, since then we could no longer recover the value $20 \mathrm{mph}$ after the possibility operator has formed the union of [-40mph, 0 ), [-30mph, 0) and [-20mph, 0). However, Rullmann's reliance on an "exactly"semantics for gradable adjectives creates a problem for him when it comes to necessity operators. Take (28).

This screw is longer than it needs to be.

The problem is that need corresponds to universal quantification, hence intersection. If the length of the screw is not the same in all accessible worlds (i.e., if more than one length is acceptable for the purpose at hand), then the intersection of singletons $\left\{\right.$ Length $_{\mathrm{w}}($ this screw $\left.)\right\}$ will be empty, and the sentence should be trivially true or deviant. If instead we intersect the intervals $(0$,

\footnotetext{
${ }^{8} \mathrm{As}$ the reader is invited to verify, the computation for (26a) is unaffected if we replace Rullmann's entry for fast with mine. The maxima of the relevant sets remain the same.
} 
Length $_{\mathrm{w}}($ this screw)], as we do on the "at least"-semantics I have subscribed to, we end up with the interval that corresponds to the minimal acceptable length for the screw. This yields the intuitively correct meaning.

My second comment concerns the non-compositionality of Rullmann's analysis. Even though he isolates little as a unit that may take different "scopes" at LF, he does not assign it its own meaning. The smallest meaningful units are little+er and little+adjective, which are idioms, so to speak. Would it be straightforward to construct a compositional version of the analysis? Looking at the entries for fast and little+fast, the contribution of little is transparent and suggests entry (29).

$$
\llbracket l i t t l e \rrbracket=\lambda \mathrm{d} . \lambda \mathrm{P}_{<\mathrm{d}, \mathrm{t}>} . \mathrm{P}(-\mathrm{d})
$$

(29) implies a semantic type and LF-syntax identical to what I proposed above: little takes a degree argument to form a little-phrase, which in turn saturates the degree argument of the gradable lexical predicate (e.g., adjective). The result of combining the little-phrase with fast locally (i.e., giving it the lowest interpretable scope) replicates Rullmann's lexical meaning for little+fast. But the little-phrase also could move, for example over a modal. So the than-clause of (1) could have two distinct LFs, just as in my analysis $(22 \mathrm{a}, \mathrm{b})$. However, with this semantics the different relative scopes of little and allowed will not give us different meanings. Whether we map each set to its negative image and then form the union of the images, or we first form a union and then transpose it to its negative, the outcome is the same. The upshot is that, even if we factor out the contribution of little as a compositional "antonymizer" in this way and give it a syntax that allows scopal freedom, we still only generate one reading, the less-than-minimum reading. For the less-than-maximum reading, we continue to need something else. Combining the little or little-phrase as interpreted by (29) directly with the er of entry (27a) is not an option, because the types don't fit, and even with an expanded repertoire of composition modes or type-shifts, this combination will not yield the meaning of little+er in (27b). So Rullmann's analysis appears to be fundamentally, and not just superficially, non-compositional.

Why does this matter, or amount to a defect? Everything else being equal, a compositional analysis is more parsimonious and thus more insightful, but that's not my only consideration. I also worry about how to extend Rullmann's analysis beyond comparatives and make it predict the emergence of analogous ambiguities in the other constructions involving little that we have looked at. Up to a point, it is clear what is called for: additional "idioms" containing little. E.g., my ad hoc meaning for I didn't realize from (18) above could be doubled up as in (30).

$$
\begin{aligned}
& \text { a. } \llbracket I \text {-didn't-realize } \rrbracket=\lambda \mathrm{P}_{<\mathrm{s}, \mathrm{dt}>} . \forall \mathrm{w} \in \operatorname{Exp}: \max (\mathrm{P}(\mathrm{w}))<\max (\mathrm{P}(@)) \\
& \text { b. } \llbracket I \text {-didn't-realize }+ \text { little } \rrbracket=\lambda \mathrm{P} . \forall \mathrm{w} \in \operatorname{Exp}: \max (\mathrm{P}(\mathrm{w}))>\max (\mathrm{P}(@))
\end{aligned}
$$


We'd then obtain the two readings of (2b) by grouping little with pay or with the embedding construction. Syntactically, of course, little is clearly inside the whclause on both readings. But it's probably not fair to use this as an objection before we have a more serious analysis of the whole construction. - The case of very little as in (2a) turns out a bit differently. Again, we first need an entry of its own for very+little.

$$
\begin{aligned}
& \text { a. } \llbracket \text { very }=\lambda \mathrm{P}_{<\mathrm{d}, \mathrm{t}>} \cdot \max (\mathrm{P})>\mathrm{L}_{\text {very, }}
\end{aligned}
$$

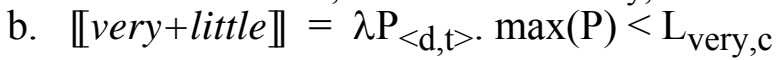

However, the entry for very in (31a) cannot figure in any reading of a sentence containing very little, because no negative degree can possibly be above the delineation interval (which better be in the positive realm if we want to be able to interpret very in sentences without little). But as it happens, we can get the two readings of an ambiguous sentence like (2a) by using very+little in both and scoping it either above or below the modal.

In summary, it is not impossible to generalize Rullmann's analysis to the full range of ambiguities involving little. The entries needed for the various littleidioms certainly display a regular pattern, which one ought to be able to distill into a meaning for a single high little, even if this still isn't unified with the low little (the antonymizer) of (29). I must suspend final judgment on the prospects of this project. For the time being, I see an advantage in the way that my own fully compositional analysis covers all the cases with a single unambiguous little. As we will see later in this paper, however, additional data bear on the issue, including some that may well suggest that all this compositionality may be too much of a good thing.

\section{More on the Distribution of the Ambiguity}

This section clarifies a bit more what my analysis of little predicts and where it needs supplemental assumptions to fit with the data. Some of the predictions are shared with Rullmann, others not.

A basic prediction of both Rullmann and the present paper is that there are (ceteris paribus) no analogous ambiguities in more-comparatives or more generally in structures missing little. Rullmann affirms this for comparatives such as (32), which he reports can't be true when Lu's speed exceeds the required mimimum but is under the speed limit; only a more-than-maximum reading is available.

(32) Lucinda is driving faster than is allowed on his highway. 
The bigger data picture is much messier, however. Schwarzschild \& Wilkinson (2002) draw attention to cases which go entirely the other way, exhibiting only what in effect is a more-than-minimum reading.

It is warmer today than it might be tomorrow.

Even the judgments on Rullmann's own examples have been challenged. Meier (2002) reports that a more-than-minimum reading for (32) becomes acceptable if Lucinda has a salient reason to want to drive as slowly as possible (she is transporting a fragile load). ${ }^{9}$ A recent proposal by Schwarzschild (2004) provides for potential ambiguity whenever a modal occurs in a comparative clause (although he does allow that individual modals may specialize for one or the other reading). There is, in effect, always one potential reading in which the modal quantification scopes over the comparison operator. ${ }^{10}$ In (32) and (33), this option happens to yield more-than-minimum readings.

If indeed there already is such an independent source of potential ambiguity in the comparative construction itself, it gets difficult to prove that little is responsible for additional readings. Notice, however, that the two readings we have considered in the less-comparative (1) cannot be reanalyzed as an instance of Schwarzschild's ambiguity interacting with a single less. If less has, say, the meaning of Rullmann's entry (27b), then a low interpretation of allowed results in the less-than-max reading. But the alternative, high, interpretation would be $\exists w \in A c c(@): \operatorname{Speed}_{@}(L u)<\operatorname{Speed}_{w}(L u)$, which is not the same as the less-than-min reading $\forall w \in A c c(@): \operatorname{Speed}_{@}(L u)<\operatorname{Speed}_{w}(L u)$. So even when we concede that more-comparatives are ambiguous too, we still seem to need a story like Rullmann's or mine to capture both readings of the lesscomparative.

\footnotetext{
${ }^{9}$ Similar observations were made to me in personal communication by E. Prince and Y. Winter. - Meier's own analysis of her data ends up denying that there really any genuine morethan-minimum readings or, for that matter, more-than-maximum readings at all. What is really going on instead is that the modal operators have more contextual restrictions than meet the eye, and they effectively range only over sets of worlds which all yield the same value for the relevant measure function. E.g., the apparent more-than-max reading of (32) really talks about the unique speed that Lu has in all the worlds that conform to the law as well as to her inclination to drive as fast as possible, and the apparent more-than-min reading about her unique speed in the worlds conforming to the law and her desire to drive slowly. I think that if this account were correct, we should expect the sentences to become uninterpretable if we specified the intended modality more explicitly (e.g., than county law permits, than she is legally entitled to). But this prediction does not seem to be borne out. The more-than-max reading still is fine for such variants of (32), and so is, for all I know, the more-than-min reading for the speakers who accept it in the first place.

${ }^{10}$ This is meant here just as a characterization of the resulting reading, not of the mechanism that produces it, which for Schwarzschild \& Wilkinson (2002) and Schwarzschild (2004) is crucially not syntactic scoping. See also Heim (2006).
} 
Away from the particularly bewildering realm of comparatives, the role of little as the culprit of ambiguity is easier to prove. Consider little-less variants of the examples in (2).

a. We can grow very much (a lot).

b. I didn't realize how much I can pay.

c. It's a shame that they let the students write so much!

These examples are not ambiguous. In particular, there are no readings paraphrasable as necessities. Also, only one of the two types of discourse contexts that worked for each example in (2) is appropriate here. E.g. (34c) unequivocally evokes students who love to write, not ones who dread it, and (34b) is about staying out of debt, not about getting quality merchandise.

A second general prediction is that ambiguity should arise in a wide variety of environments for little, essentially whenever we have anything quantificational taking scope over the gradable predicate. Again, the case of lessthan-clauses is probably the hardest of all to study, because of the independently quirky behavior of quantifiers in comparative clauses. In a nutshell, most if not all DP and adverbial quantifiers effectively scope out of the than-clause they appear in and hence won't get a chance to interact with a little-phrase there in the first place. Whatever the explanation for this may be, ${ }^{11}$ it means that Mary ate less than every guest did is effectively 'for every guest $\mathrm{x}$, Mary ate less than $\mathrm{x}$ did', and we shouldn't expect scope-ambiguity due to little any more than in the simple Mary ate less than John did.

So what besides possibility modals is there that we should expect to show ambiguous scope relative to little? Perhaps not much. If Schwarzschild \& Wilkinson (2002) as amended by Schwarzschild (2004), or Kennedy (1997) as amended by Heim (2001), are on the right track, the only quantifiers capable of intervening between a degree variable and its binder may be modal verbs and not even all of those. Besides the possibility modals be allowed and can that I have already exemplified, this leaves necessity modals such as need and have to. If my analysis of little is correct, these should participate in ambiguities as well, and I believe this is borne out.

(35) a. It's a shame that the students are required to write so little!

b. I didn't realize how little I have to spend

(i) ... to get a decent meal.

(ii) ... if I want to have something left at the end of the trip.

c. Paul ate less than was necessary

(i) ... to comply with the diet.

(ii) ... to maintain his weight.

\footnotetext{
${ }^{11}$ See again Schwarzschild \& Wilkinson (2002), Heim (2006), and references cited there.
} 
(35a) can be used to express dismay that the students don't have to write more, and also to express dismay that they are constrained by such strict page limits. In $(35 \mathrm{~b}, \mathrm{c})$, I have added continuations that are meant to facilitate one or the other reading. (35b-i) means that I expected I would have to spend more. (35b-ii) means I thought I would be able to spend more. In (35c-i), the claim is that Paul ate even less than the strictures of the diet would have allowed him to eat. And in (35c-ii), we are saying that he didn't eat enough to maintain his weight. All these readings can be captured by manipulating the relative scopes of little and necessity. Wide scope for little yields the first-mentioned reading of (35a), the reading of (35b) in the context of continuation (i), and the reading of (35c) with continuation (ii). The reverse scoping gives the other readings.

Incidentally, these examples illustrate a curious consequence of the analysis: The presence of little kind of destroys the semantic distinction between necessity and possibility modals. We end up with the same two readings whether we use one or the other. Since little is negation, and necessity and possibility are duals, little scoping over one means the same as little scoping under the other. Disturbing though this may be, it does appear to be consistent with the evidence.

A third prediction I want to highlight is this: Though I've been concentrating on scopal interaction among elements in the than-clause, my analysis derives analogous interactions in the matrix of less-comparatives. If the matrix-clause happens to contain a modal operator, it should be able to scope above or below the matrix instance of little in just the way that an operator in the than-clause scopes above or below its covert counterpart there. Here are some examples. Two of them have necessity operators and two have possibility operators, and two have simple than-clauses, whereas the other two have parallel structures with (matching) modals in the main and subordinate clauses.
a. I can pay less than you just paid.
b. I can pay less than you can.
c. He had to write less than he actually did.
d. He has to write less than she has to write.

If we scope little below all the modals, the readings we obtain are these: (36a) means that it is possible for me to pay less than what you just paid. (36b) means that the lowest payment I can get away with is lower than the lowest payment that you can get away with. (36c) means that he wrote too much; i.e., it was required of him to limit his writing to a smaller amount. (36d) means that he is subject to a stricter page limit than she is. - If, on the other hand, we scope little above each of the modals, we get readings that amount to the following: (36a) means that I can't pay as much as what you just paid. (36b) means that my spending limit is stricter than yours. (36c) means that he wrote in excess of what was required of him. And (36d) means that he is subject to a less demanding writing-requirement 
than she is (i.e., he can get away with a smaller number of pages than she can). Not all of these readings are perfectly easy, but they all seem to be possible and can be brought out in suitable pragmatic settings.

Readers of my previous work may be wondering how the present analysis of these examples relates to the one in Heim (2001). There I did not decompose less, but treated it as a basic comparison operator, with a meaning equivalent to little+er in (27b) above. Recall that LFs with little+er are systematically equivalent to LFs in which little is in the immediate scope of er and of the erphrase. This being so, we can see how I was able to capture the second set of the readings described above. We might think, however, that I should not have been able to account for the first set of readings.

Actually the situation is more complicated. In Heim (2001), I allowed variable scope for the less-phrase as a whole. In the current theory too, there is not just the scope of the little-phrase to consider, but the scope of the er-phrase as well. Schematically, we have all of the following scope constellations for a lesscomparative with a matrix modal.

present proposal:
a. er-phrase $>$ little-phrase $>$ modal
b. modal $>$-er-phrase $>$ little-phrase
c. - er-phrase $>$ modal $>$ little-phrase

Heim (2001):

d. less-phrase $>$ modal

e. modal $>$ less-phrase

(a) and (d) are equivalent and yield the readings described as wide-scope-little readings for (36) above (i.e., the second set of paraphrases). But (b) and (e) are also equivalent, and moreover there is no truth-conditional difference between (b) and (c). So it turns out that with or without decomposition of less into er and little, we get a two-way scopal ambiguity. Indeed, the two readings of (36a) and (36c) were correctly predicted by Heim (2001) and therefore do not constitute evidence for the decomposition of less. All we can say is that they are consistent with the decompositional analysis.

This is not the case for the examples in (36b) and (36d), however, which have modals in both clauses. Heim (2001) did not generate quite the right truthconditions for both readings of these sentences. ${ }^{12}$ Consider the first meaning I described for (36b): the lowest payment I can get away with is lower than the lowest payment that you can get away with. This is correctly expressed by the LF in $(38 \mathrm{a})$, but not by the one in (38b).

a. $\left[\text { er than } \mathrm{wh}_{3} \text { can }\left[\mathrm{t}_{3} \text { little }\right]_{4} \mathrm{I} \text { pay } \mathrm{t}_{4}\right]_{1}$ can $\left[\mathrm{t}_{1} \text { little }\right]_{2} \mathrm{I}$ pay $\mathrm{t}_{2}$

b. can $\left[\text { less than } \mathrm{wh}_{4} \text { can } \mathrm{I} \text { pay } \mathrm{t}_{4}\right]_{2}$ I pay $\mathrm{t}_{2}$

\footnotetext{
${ }^{12}$ This was pointed out to me by R. Schwarzschild in a set of written comments on Heim (2001).
} 
Despite the equivalence of $(37 \mathrm{~b}, \mathrm{c})$, and even if we make provisions to evaluate the embedded clause in the actual world (rather than the world introduced by the modal), (38b) has a substantially different than-clause than (38a). It means that the lowest possible payment by me is below your upper spending limit. This is probably not a possible reading for the sentence at all, and even if it is, it is not the one we were talking about. Heim (2001) had no resources to capture the intended reading. - To summarize this discussion of what the present proposal predicts about scopal ambiguities in the matrix clauses of less-comparatives: the data are consistent with the predictions, though as long as there are modals only in the main clause, the evidence does not specifically favor decomposition of less into $e r$ and little over an alternative theory which has an unanalyzed but scopally mobile less.

\section{Monotonicity Properties and Negative Polarity Licensing}

One of the impressive accomplishments of Rullmann's analysis is the light it throws on a puzzling pattern in the distribution of NPIs. Ordinary (more-) comparatives are known to license NPIs in their than-clauses, which is standardly explained by a semantics for er that is downward-entailing (DE). The meaning for er that I adopted in (25) is among the ones that have this property (as are various other plausible meanings). On the other hand, the most simple-minded meaning for less, namely (27b), is not DE - in fact, it is upward-entailing (UE). So one might have expected less-comparatives not to license any NPIs in their than-clauses. But the facts are otherwise and NPIs do occur in less-than-clauses.

a. Kaline ate less today than she ever did before.

b. Kaline ate less than you care to know.

Rullmann's solution to this puzzle is that the UE little+er appears in only one of the readings; the other reading involves the DE er. This immediately explains why NPIs are possible in the than-clauses of less-comparatives. To license them, we just need to bracket little with the adjective. The NPI will then be in the (immediate) scope of a DE operator, er. There also is a further prediction, namely that the appearance of an NPI should disambiguate the truth-conditions. Rullmann illustrates this with the minimal pair in (40).

a. The helicopter was flying less high than a plane can fly.

b. The helicopter was flying less high than any plane could fly.

For (40a), he observes a less-than-maximum reading on which the helicopter's altitude is below the maximal altitude that a plane can reach, and a less-thanminimum reading on which its altitude is below the minimal altitude that a plane 
is forced to maintain. For (40b), he reports that only the less-than-minimum reading is possible. We can also see that the prediction is correct for (39a). If little were grouped with er in this sentence, it ought to mean that Kaline ate less today than on her most voracious days in the past. But in fact we understand that she ate less than on the days of even her poorest appetite.

My own analysis inherits part but not all of this story. Wherever NPIs have the option of scoping higher than little, they will be licensed in the same way as in more-comparatives, by the DE er. Like Rullmann, I thus explain why NPIs in less-than-clauses will not cause ungrammaticality. Beyond that, however, my predictions are not quite the same. First, my little has more possible scopes than all the way up or all the way down. In a sentence like Rullmann's (40b), it could also be scoping below the any-subject yet above the modal could. This would make the NPI okay but still give rise to a less-than-maximum reading. I therefore do not have an explanation for the judgment that Rullmann reports. This is a problem. I would have liked to hold out a hope that the intermediate scope readings I predict can be found to exist, once one looks for them carefully enough. But although the computations are challenging and the judgments tenuous, I've come to be persuaded that Rullmann's descriptive generalization really is correct. Here is another pair of examples to ponder.

a. Ich fuhr weniger schnell, als ich's gedurft hätte.

I drove less fast than I it be-allowed had-subj

'I drove less fast than I would have been allowed'

b. Ich fuhr weniger schnell, als ich's jemals gedurft hätte.

I drove less fast than I it ever be-allowed had-subj

'I drove less fast than I ever would have been allowed'

(41a) is chosen to make a less-than-maximum reading especially natural. For this reading, wenig ('little') must be scoping over the modal. If we retained the same relation in (41b) and positioned the NPI jemals ('ever') so as to produce the overall scoping er $>$ ever $>$ little $>$ allowed, the NPI would be licensed, and the sentence would mean that I drove below the lowest of the various speed limits that were posted in the past. But this is not a possible reading. Instead, I get a spontaneous inference from (41b) that I did something forbidden, and when I reflect on what it means more specifically, it's that I drove below the lowest minimum speed ever posted.

My approach has a further difficulty, stemming from the fact that the little-phrase is itself a DE operator (unsurprisingly, given that it's basically negation). One should therefore expect NPIs to be happy in its scope. No disambiguating effect should occur, because the NPI is just as licensed in the immediate scope of little as in the immediate scope of er. But what Rullmann's facts suggest instead is that the two DE operators er and little cancel each other out, and they jointly make a non-DE environment for the elements that are in the 
scope of both. This is problematic for me because it does not seem to be the way in which NPI-licensing normally works. If we embed one DE operator under another, NPIs under the lower one still are possible.

John refused not to divulge anything.

One might note, however, that such examples are not entirely easy to parse and perhaps are really felicitous only when there is a previous discourse from which the embedded part is repeated. E.g., We asked people not to divulge anything, but John refused not to divulge anything. Moreover, when examples of this type are presented in isolation and there is an option of scoping the NPI between the two $\mathrm{DE}$ operators, this tends to be the preferred reading.

He never refuses to discuss anything.

Perhaps these considerations justify dismissing the problem. Perhaps an NPI could in principle be licensed under little, but it's just too hard to set up the appropriate discourse context to make this happen in practice. I am sceptical of this response, however, especially in light of the other problem we just saw, regarding unattested intermediate-scope readings. More plausibly, what we have found in this section points to a distinctive advantage of Rullmann's analysis over mine: When little scopes out of its host-phrase at all, it always scopes immediately below er and in fact the two act as an inseparable unit (a single UE operator). I do not see at present how to reintegrate this feature into my analysis without sacrificing its compositionality.

\section{Decomposing Antonyms?}

So far I have disregarded an additional piece of data that Rullmann discusses and aims to account for. The ambiguity that emerges in less-comparatives is likewise present in more-comparatives based on marked antonyms. For example, (44) has the same two readings as (1).

(44) Lucinda is driving more slowly than is allowed on this highway.

Rullmann proposes to account for this by positing that more slowly is yet another way to spell out the same three morphemes er, little, and fast. Moreover, he suggests that the grouping of these three items at LF is completely independent of their grouping at PF. As we saw above, at LF we can have either little+er and fast, or else er and little+fast, giving us respectively the less-than-maximum and less-than-minimum readings. At PF, we also have a choice between fusing little with er or with fast, and there these fusions are spelled out respectively as less 
and as slowly. Crucially, the bracketing choices that we make at LF and at PF in a given derivation are independent of each other. We have a total of $2 \times 2$ options, and this yields the prediction that either surface sentence can have either reading.

This analysis could be carried right over into my own version of the decompositional analysis. A simple sentence such as $L u$ is slow would have the following analysis.

$$
\begin{aligned}
& \text { LF: } \quad \text { POS }_{1}\left[\mathrm{t}_{1} \text { LITTLE }_{2} \text { Lu is } t_{2}\right. \text { FAST } \\
& \text { meaning: Speed }(\mathrm{Lu})<\mathrm{L}_{\mathrm{c}}
\end{aligned}
$$

There will evidently have to be more than this to a serious theory of antonymy, but that's a project for another occasion. ${ }^{13}$ What I want to focus on here are the specific implications of Rullmann's hypothesis that the groupings at LF and at PF are independent of each other. I will call this the Independence Hypothesis. The Independence Hypothesis predicts that, if we have an adjective $\alpha$ and its marked antonym $\beta$, we can always substitute $\beta$-er for less $\alpha$ in a given sentence without changing its range of available readings. The equivalence that Rullmann observed between (44) and (1) points to the correctness of this prediction. But if we look at a wider range of examples, it does not appear to be holding up.

Consider a scenario I constructed in Heim (2001). John and Mary both are supposed to be in Boston by 8pm at the latest, and they are both driving there. It is 5:30pm, and John is just about to set out from Providence RI, whereas Mary is leaving from New Haven CT. Evidently, since New Haven is a longer way from Boston than Providence is, (46a) is true, on a natural reading. Another sentence which is also true, in fact a paraphrase of (46a)'s intended reading, is (46b). But (46c) is arguably false: John doesn't need to drive more slowly, he just has the option to. (It doesn't hurt if he arrives early. He can drive as fast as he wants to.)

a. Mary needs to drive faster than John needs to drive.

b. John needs to drive less fast than Mary needs to drive.

c. John needs to drive more slowly than Mary needs to drive.

Another triplet to make the same point is (47).

\footnotetext{
${ }^{13}$ Many challenges arise from the fact that little $\alpha$ is not always, perhaps even never, exactly synonymous with the antonym of $\alpha$. Some of the differences (e.g., between less good and worse) may be confined to non-truth-conditional dimensions of meaning, but others are clearly truthconditional (e.g. the contrasts in pairs like little known and unknown, which were pointed out to me by Y. Winter and E. McCready). In the following discussion, I try to stick to non-evaluative, open-scaled, adjectives in the comparative (like less fast-slower, less old-younger), which do seem to form truth-conditionally equivalent pairs in simple sentences. It remains to be seen, of course, if the conclusions that I reach this way can survive in a richer, more adequate theory.
} 
(47) The older pupils get the single rooms on the top floor, but ...

a) girls have to be older than boys (before they qualify for this privilege).

b) boys have to be less old than girls (before they qualify ...).

c) \#boys have to be younger than girls (before they qualify ...)

(47a) and (47b) share a plausible reading that amounts to a charge of sexism, but (47c) doesn't make any sense in this discourse.

Testing minimal pairs of this kind in degree constructions other than comparatives is made difficult by the ungrammaticality, at least in English, of phrases like *how little fast, * so little tall. To the extent we can work around this, though, I believe we see further counterexamples to the Independence Hypothesis.

a. ?Es ist ein Skandal, wie wenig schnell man hier fahren darf.

it is a scandal how little fast one here drive may

b. Es ist ein Skandal, wie langsam man hier fahren darf.

it is a scandal how slow one here drive may

(48a) is marginal, but insofar as I can disregard this, I find it can express disapproval of an overly restrictive upper speed limit. (48b), by contrast, means only that there ought to be a higher required minimum speed. ${ }^{14}$

I interpret the data in (46) - (47) as problematic for the Independence Hypothesis. These examples indicate that the constructions which have little or less on the surface allow more possible readings than their variants with lexical antonyms. More specifically, the readings which we see getting lost in the attempted paraphrases are the just ones we have analyzed as involving non-local scope for little. This suggests that, contrary to the Independence Hypothesis, spelling out little+adjective as a lexical antonym is not compatible with scoping little at LF. An obvious way to amend the theory minimally so that it will make this prediction is to forego the decomposition of slow altogether, and instead give a lexical entry that has the contribution of degree-negation already built in.

$$
\llbracket \text { slow }=\lambda \mathrm{d} . \lambda \mathrm{x} . \operatorname{Speed}(\mathrm{x})<\mathrm{d}
$$

An alternative option is to appeal to the syntactic islandhood of lexical units, so that even if slow is represented as little fast, little cannot move out of it.

Choices of implementation aside, however, any revision of the theory along these lines will leave unexplained the evidence that compelled Rullmann to the Independence Hypothesis in the first place. If the degree-negation inside slow

\footnotetext{
${ }^{14}$ Interestingly, however, the less-than-maximum reading reemerges when I add nur ('only'), as in Es ist ein Skandal, wie langsam man hier nur fahren darf. This calls for further investigation.
} 
is really frozen in place, how can it be that (44) is ambiguous? In particular, how can this sentence have a less-than-maximum reading?

Here is one attempt to resolve the dilemma. Notice that the ambiguous example (44) differs in the following way from the unambiguous (46c), (47c), and (48b). In (44), the relevant scopal interaction is not actually in the overt matrix clause, but rather in the embedded clause, which is partially elided. Specifically, the problematic less-than-maximum reading in (44) must be derived by giving non-local scope to the covert copy of little that we posit as part of the covert clausal complement of allowed. In (46c) etc., by contrast, the relevant little is in a fully overt clause. Might we be able to exploit this difference to explain away the apparent evidence that (44) gave for the Independence Hypothesis?

Suppose that slow indeed is never decomposed. So wherever we have slow in the representation, the degree-negation associated with it takes minimal scope. This correctly predicts the non-ambiguity of (46c) and its kin. As for (44), suppose the than-clause does not actually have to contain an instance of slow; rather it may contain (covertly, of course) separate instances of little and fast. Only the matrix clause of this sentence necessarily has an instance of slow. This makes possible the following derivation for the less-than-max reading of (44).

Lu drive [[er than allowed Lu drive wh little fast] slow]

LF: [er than $\mathrm{wh}_{3}\left[\mathrm{t}_{3} \text { little }\right]_{4}$ allowed Lu drive $\mathrm{t}_{4}$ fast $]_{1}$ Lu drive $\mathrm{t}_{1}$ slow

The obvious question, of course, is what theory of ellipsis (or reconstruction, or recoverability of deletion) will make this kind of derivation legitimate, despite the mismatch between the lexical items that make up the two clauses. Encouraging in this regard is the trend in the recent ellipsis literature to place an increasing burden on conditions of semantic identity. In the wh-clause in (50), only the predicate is allowed is pronounced. Plausibly, this bears focus, and plausibly, occurring in actuality is a relevant alternative to being allowed to occur. We can then show that the wh-predicate has a focus-value which contains the regular semantic value of matrix-predicate $\left(\lambda_{1}\right.$. Lu drive $t_{1}$ slow $)$ as an element. The semantic equivalence between slow and little fast is sufficient for this, and the syntactic mismatch between the clauses is irrelevant. If that is all it takes to license the ellipsis, we are in business.

It is highly doubtful, however, that we can get away with such permissive mechanisms of ellipsis licensing. Here is another example, which ought to be parallel.

Lu is driving slowly. It's allowed.

The second sentence of (51) cannot mean that $\mathrm{Lu}$ is required to drive slowly. Yet it should be able to express this meaning if the LF could be (52). 
POS $_{1}$ Lu drive $t_{1}$ slow. POS $2\left[t_{2} \text { little }\right]_{3}$ allowed Lu drive $t_{3}$ fast.

Since such a reading is totally unavailable, I fear that we are not on the right track.

A different idea is that (44) might be another instance of the phenomenon we have already had to acknowledge in connection with the more-comparative (32). In other words, perhaps the less-than-maximum reading actually comes about by the modal scoping over the matrix (in Schwarzschild-Wilkinsonian fashion). If so, then with (undecomposed) instances of slow in both the matrix and the than-clause, (44) will mean that there is an accessible world w such that Lu's actual speed is below her speed in w, which is true just in case she is driving below the allowable maximum. This is probably the more plausible solution.

In sum, there is rather convincing evidence against the Independence Hypothesis, suggesting that even if slow means the same thing as litte fast, it does not contain a scopally mobile little. There is hope that we can explain away the apparent support the hypothesis first received from Rullmann's observation about comparatives like (44), though my efforts in this regard remain preliminary.

\section{References}

Heim, Irene: 2001, 'Degree Operators and Scope', in C. Féry and W. Sternefeld (eds.) Audiatur Vox Sapientiae, Akademie-Verlag, Berlin, 214-239.

Kennedy, Christopher: 1997, Projecting the Adjective. Doctoral Dissertation, UC Santa Cruz (published by Garland Press).

Meier, Cécile: 2002, 'Minimality and Maximality in Comparatives', in G. Katz, S. Reinhard, P. Reuter (eds.) Proceedings of Sinn and Bedeutung VI, Publications of the Institute of Cognitive Science, University of Osnabrück, $275-287$.

Rullmann, Hotze: 1995, Maximality in the Semantics of Wh-Constructions, Doctoral Dissertation, UMass Amherst.

Schwarzschild, Roger and Karina Wilkinson: 2002, 'Quantifiers in Comparatives: A Semantics of Degree Based on Intervals', Natural Language Semantics 10, 1-41.

Schwarzschild, Roger: 2004, 'Scope-Splitting in the Comparative', handout from MIT colloquium, http://www.rci.rutgers.edu/ tapuz/pubs.htm

Stechow, Arnim von: 2005, 'Temporal Comparatives: Früher ('earlier'), Später ('later')', handout, http://www2.sfs.nphil.uni-tuebingen.de/ arnim10/Handouts/index.html

Seuren, Pieter A.M.: 1979, 'Meer over minder dan hoeft', De nieuwe taalgids 72, 236-239. 